\title{
Beyond mining
}

\author{
Global demand for raw materials is at an all time high, and rising. As mining companies scale up their \\ operations in response, society needs to develop strategies to keep damage to a minimum.
}

The Earth's supply of metals and minerals is large. Nevertheless, production capabilities are not endless, and availability cannot always be adjusted fast enough to meet changes in demand. The shortage of rare-earth elements that developed over the past year is a case in point. China, responsible for more than $90 \%$ of the world's supply of these elements, prioritized its own economy's demand and started to limit export. Worldwide disruptions were the result (http://go.nature.com/ wSNoFm). The realization of its industry's vulnerability has prompted the European Union, among others, to identify 14 critical raw materials: elements that are economically important, yet at risk of supply disruption (http://go.nature.com/jxy6yo).

Geologists, too, have responded to the rising interest in mineral supply. The raw materials crisis - regarding rare-earth elements as well as other commodities has been the focus of special sessions at the large geoconferences this year, including the General Assembly of the European Geosciences Union in April and the Goldschmidt conference in August. More recently, one of seven sessions at the Fermor meeting organized by the British Geological Society in London, on 'Ore deposits in an evolving Earth', (http://www.geolsoc.org.uk/ fermor2011) was devoted to the availability of mineral commodities, and included the viewpoint from representatives of the mining industry as well as academia.

Concern over the limits to commodity availability stems not so much from the fear that resources will run out. 'Peak metal' the anticipated turning point from globally increasing to decreasing production when minable deposits become scarce - is not yet on the horizon, according to a broad consensus at the meeting (although dissenting views do exist, for example, Nature Geosci. 1, 720-721; 2008). But however much the Earth's crust still has in store, surging demand, combined with monopolies by companies or countries, could lead to bottlenecks and shortages.

Gus Gunn of the British Geological Survey identified three main factors behind the steep rise in demand at the Fermor meeting: population increase, urbanization that is accompanied by a rise in the standard of living, and the development of new technologies whose components and gadgets

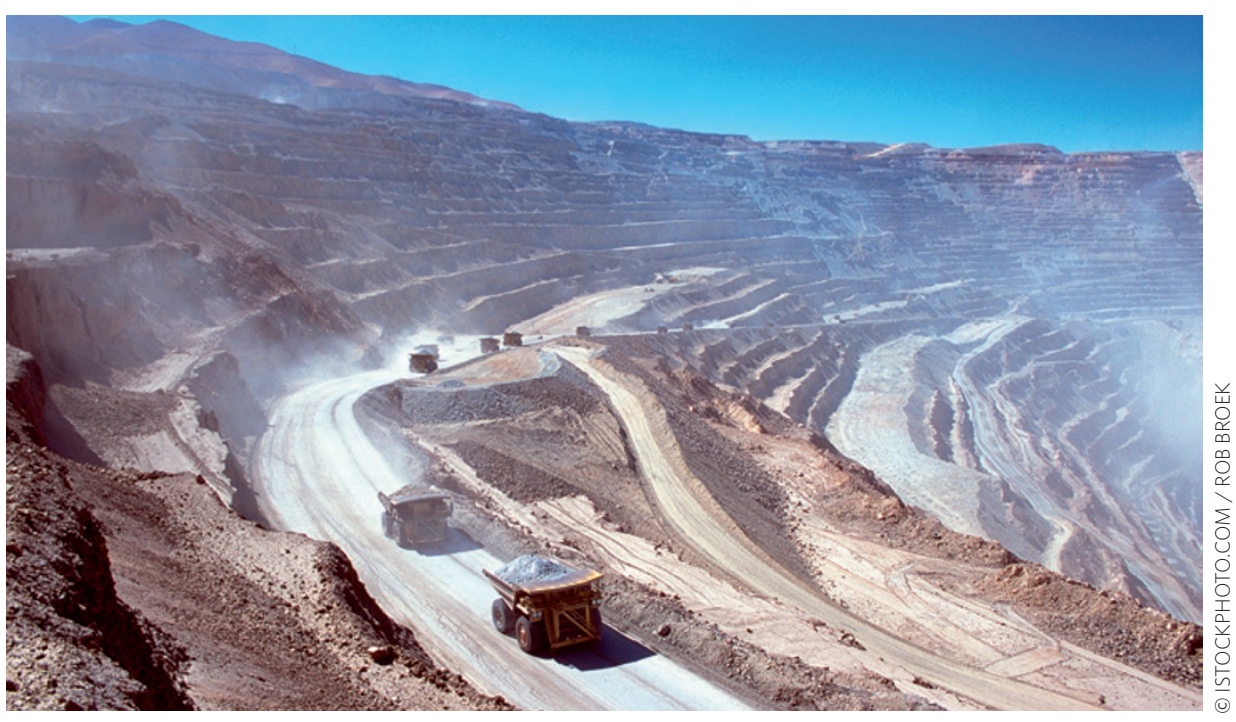

are based on an ever broader base of elements. All three trends are likely to continue into the future. And, as Thomas Graedel of Yale University noted, the stocks and flows of only a handful of metals are currently the focus of intense research, whereas mobile phones, for example, make use of a much wider range of the elements of the periodic table. This research gap needs to be closed.

There has never been a better time for young people to enter into the field of economic geology and join a mining company, concluded one of the meeting organizers at the student session that preceded the meeting. Yet the subject does not seem to entice large numbers of students. Bad press about the safety of mining operations, environmental damage and reckless exploitation of irreplaceable mineral resources in the developing world (http://go.nature. $\mathrm{com} /$ pamf8Q), do not make the field look attractive.

According to a presentation on 'The moral case for mining' by Michael Harris of the mining company Rio Tinto, the mining industry in principle acknowledges its responsibility to society and the environment. The largest mining projects are now approaching a scale that matches the size of oil exploration endeavours, in terms of the projects' share of the host country's economy. As operations become more visible, the industry fears a rise in widespread antagonism, similar to that seen by the big oil companies in the past decade. Local hostility would make their operations more difficult. To maintain a positive public image, large mining companies are publicizing their internal environmental and health and safety regulations and argue with their reliance on good local relations.

To condemn the large miners would be too simple: their products are in demand, and as one audience member pointed out, if the mining companies suddenly stopped producing, they would be hated much more than they are for their operations. But in light of the ongoing trend in the demand for metals and minerals, and given expectations that the exploration of ever deeper, riskier and lowergrade deposits will become economically viable as prices go up, standards for mining operations need to be debated widely and openly. Regulations of acceptable ecologic as well as economic impacts of mines on their host countries need to be developed - and policed - by society as a whole.

However it is conducted, mining will bring destruction as well as wealth. A global debate is needed to establish an acceptable environmental and social price of technological advance, and to determine how much of the profit should benefit those who live near a mine, rather than going to the companies' shareholders. In this debate, the expertise of geologists and environmental scientists, inside the mining industry and out, will be in demand. 